\title{
Tracking changes in bioavailable Fe within high-nitrate low- chlorophyll oceanic waters: A first estimate using a heterotrophic bacterial bioreporter
}

\author{
Cécile E. Mioni, ${ }^{1}$ Sara M. Handy, ${ }^{1,2}$ Michael J. Ellwood, ${ }^{3}$ Michael R. Twiss, ${ }^{4}$ \\ R. Michael L. McKay, ${ }^{5}$ Philip W. Boyd, ${ }^{6}$ and Steven W. Wilhelm ${ }^{1}$
}

Received 10 February 2005; revised 12 October 2005; accepted 14 October 2005; published 24 December 2005.

[1] It is conventional knowledge that heterotrophic bacteria play a key role in the biogeochemical cycling of oceanic carbon. However, only recently has their role in marine iron $(\mathrm{Fe})$ biogeochemical cycles been examined. Research during this past decade has demonstrated an inextricable link between Fe chemistry and the biota, as $>99 \%$ of Fe in marine systems is complexed to organic chelates of unknown but obviously biotic origin. Here we present a novel approach to assess and compare Fe bioavailability in low Fe HNLC waters using a bioluminescent bacterial reporter that quantitatively responds to the concentration of bioavailable Fe by producing light. Originally tested in freshwater environments, this study presents the first characterization of this halotolerant reporter organism in a defined seawater medium and then subsequently in marine surface waters. Laboratory characterizations demonstrate that this reporter displays a dose-dependent response to Fe availability in our defined marine medium. Field tests were performed during the 10-day mesoscale FeCycle experiment (February 2003) in the Pacific sub-Antarctic high-nitrate low-chlorophyll region. Data from both biogeochemical measures and bioreporter assays are provided which describe how the bioreporter detected changes in Fe bioavailability that occurred during a natural shift in ambient dissolved Fe concentrations $(\sim 40 \mathrm{pM})$. Our data explore the use of heterotrophic bioluminescent reporters as a comparable tool for marine ecosystems and demonstrate the potential utility of this tool in elucidating the relationship between Fe bioavailability and $\mathrm{Fe}$ chemistry in complex marine systems.

Citation: Mioni, C. E., S. M. Handy, M. J. Ellwood, M. R. Twiss, R. M. L. McKay, P. W. Boyd, and S. W. Wilhelm (2005), Tracking changes in bioavailable Fe within high-nitrate low-chlorophyll oceanic waters: A first estimate using a heterotrophic bacterial bioreporter, Global Biogeochem. Cycles, 19, GB4S25, doi:10.1029/2005GB002476.

\section{Introduction}

[2] Iron $(\mathrm{Fe})$ is an essential micronutrient for microorganisms since it serves as a cofactor for a wide variety of enzymes and redox catalysts [Raven, 1990; Geider and Laroche, 1994; Tortell et al., 1999]. Although absolute requirements vary, it has been estimated from laboratory studies that cultured heterotrophic bacteria require a min-

\footnotetext{
${ }^{1}$ Department of Microbiology and Center for Environmental Biotechnology, University of Tennessee, Knoxville, Tennessee, USA.

${ }^{2}$ Now at College of Marine Sciences, University of Delaware, Lewes, Delaware, USA.

${ }^{3}$ National Institute of Water and Atmosphere, Hillcrest, Hamilton, New Zealand.

${ }^{4}$ Department of Biology, Clarkson University, Potsdam, New York, USA.

${ }^{5}$ Department of Biological Sciences, Bowling Green State University, Bowling Green, Ohio, USA.

${ }^{6}$ National Institute of Water and Atmosphere, Dunedin, New Zealand.

Copyright 2005 by the American Geophysical Union. 0886-6236/05/2005GB002476\$12.00
}

imum Fe concentration of $\sim 10^{-8} M$ for growth [Braun and Hantke, 1997], yet such Fe concentrations are rarely measured in oceanic surface waters. Low inputs of $\mathrm{Fe}$ from aeolian and/or deep water upwelling sources, combined with rapid biological assimilation as well as abiotic removal due to scavenging by sedimenting particles, result in total dissolved $\mathrm{Fe}(\mathrm{DFe})$ concentrations ranging from $0.02 \mathrm{n} M$ to $1 \mathrm{n} M$ in many pelagic marine systems [Johnson et al., 1997; Measures and Vink, 2001; Takata et al., 2004]. Ecosystem-scale perturbation experiments have demonstrated that these low ambient Fe concentrations control phytoplankton growth, community composition and ecosystem function in large areas of the world's ocean, including the equatorial Pacific [Coale et al., 1996], the subarctic Pacific [Tsuda et al., 2003; Boyd et al., 2004] and the Southern Ocean [Boyd et al., 2000; Gervais et al., 2002; Coale et al., 2004]. In these regions, mesoscale "Fe enrichments" have resulted in phytoplankton blooms and a switch in the ecosystem from recycling- to exportdominated planktonic communities [Bishop et al., 2004; Buesseler et al., 2004]. 
Table 1. Composition of BESAW Medium as Modified From Berges et al. [2001]

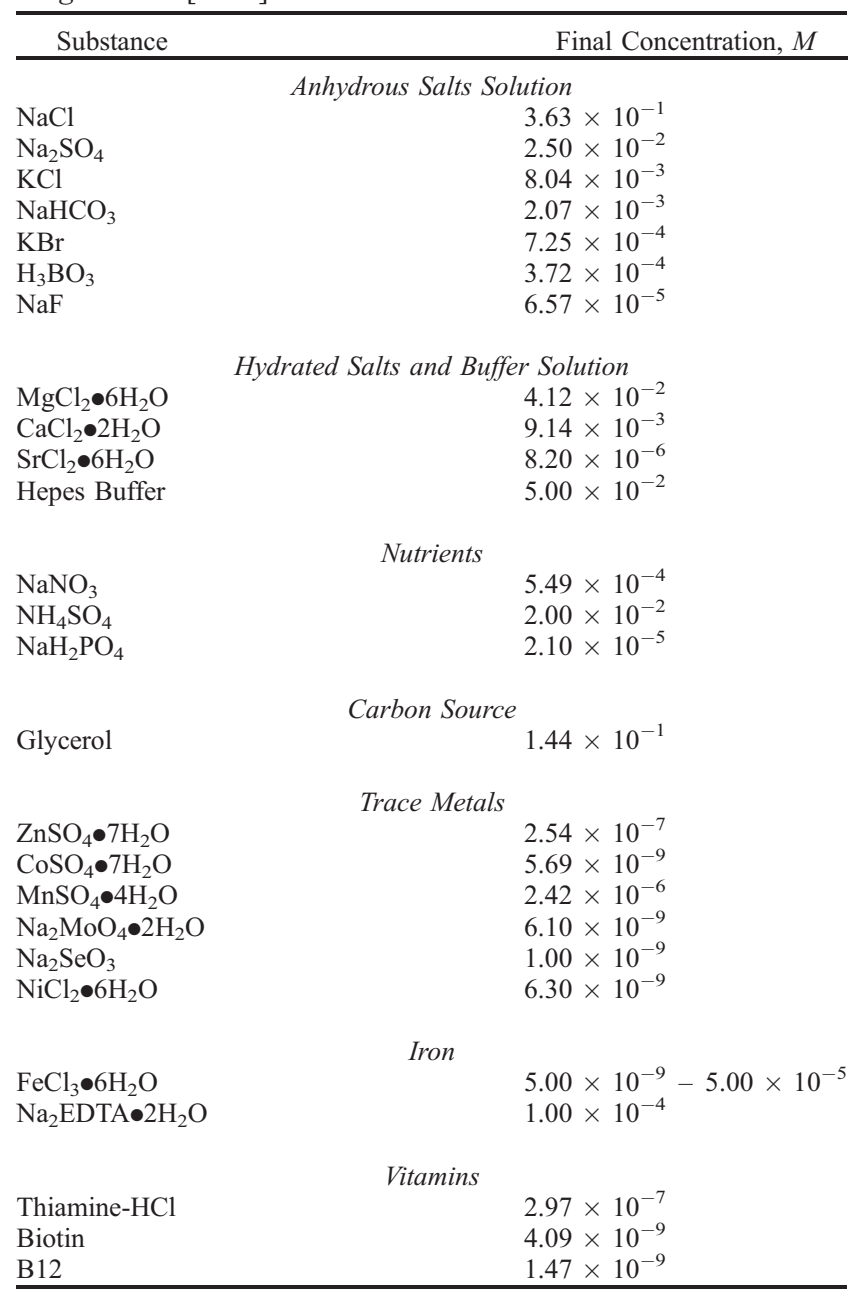

${ }^{a}$ Nutrients and salts were prepared as two-time concentrated stocks solutions, Glycerol was added to the salt solution as $30 \mathrm{~mL}$ of a separately Chelex-100 treated stock solution $(35 \% \mathrm{v} / \mathrm{v}$, in BESAW salts), and trace metals and vitamins were added from $\times 1000$ and $\times 10,000$ stock solutions, respectively.

[3] Although Fe-deficient surface seawaters are generally dominated by microbial food web communities containing a high proportion of picoplankton $(0.2-2 \mu \mathrm{m})$, both laboratory and field experiments suggest that autotrophic [Wilhelm, 1995; Achilles et al., 2003] and heterotrophic [Pakulski et al., 1996; Hutchins et al., 1999a, 2001a; Weaver et al., 2003; Arrieta et al., 2004] bacterioplankton components may be Fe-limited as well. Despite larger cell surface area to volume ratios that should give bacterioplankton an advantage [Eldridge et al., 2004, and references therein], empirical models suggest that bacteria are disadvantaged compared to phytoplankton due to slower uptake kinetics and their higher $\mathrm{Fe}: \mathrm{C}$ requirements [Maldonado and Price, 1999]. Therefore the predominance of bacterioplankton in most HNLC regions is quite puzzling if only total DFe concentrations are considered. Indeed, it has been suggested that changes in the chemical speciation and size-class partitioning of Fe exert more influence than the total concentration of DFe on the planktonic group(s) that dominate the specific communities [Hutchins et al., 1999b, 2001a; Poorvin et al., 2004; Wells and Trick, 2004]. Unfortunately, while physiological proxies such as flavodoxin and ferredoxin have been developed to correlate algal $\mathrm{Fe}$ stress to water column $\mathrm{Fe}$ concentrations [McKay et al., 2005], there are no analytical tools currently available which can be employed to compare the fractions of $\mathrm{Fe}$ in seawater that are biologically available to either phytoplankton or bacteria [Gerringa et al., 2000; Wells and Trick, 2004].

[4] Here we describe a new approach to assess $\mathrm{Fe}$ bioavailability in seawater: a heterotrophic bacterial reporter that responds specifically to Fe stress by producing a quantifiable bioluminescent signal. In the current study we have used this new tool to determine whether changes in bioavailable Fe occurred within a surface seawater patch labeled with sulfur hexafluoride $\left(\mathrm{SF}_{6}\right)$. The halotolerant isolate Pseudomonas putida was genetically engineered to produce light (luminescence) when the native high-affinity Fe transport system(s) of the host cell are derepressed [Mioni et al., 2003], resulting in the bioreporter strain $P$. putida FeLux. This enables the detection of variations in bioavailable $\mathrm{Fe}$ in situ. In the present study, we describe the initial laboratory characterization of this $P$. putida Fe-dependent bioreporter in a chemically defined and modeled synthetic seawater medium (BESAW) that can be used as a standard for comparison between systems. We also present a set of field measurements performed in late austral summer (February 2003) in the sub-Antarctic Pacific region during the 10-day "FeCycle" mesoscale study. To the best of our knowledge, this is the first portable tool available to directly assess the bioavailability of $\mathrm{Fe}$ to a heterotrophic prokaryote in marine systems.

\section{Material and Methods}

\subsection{Strain and Laboratory Calibration}

[5] Pseudomonas putida FeLux [Mioni et al., 2003] stock cultures were maintained on Pseudomonas Isolation Agar (Remel) supplemented with $50 \mu \mathrm{g} \mathrm{mL}^{-1}$ of tetracycline (Tc) at $30^{\circ} \mathrm{C}$. Prior to the experiment, several colonies were screened. The colony with the largest dynamic range of light production relative to the control (no addition) after an addition of $\mathrm{Fe}(1.5 \mathrm{n} M)$ or desferrioxamine $\mathrm{B}$ (DFB, $1.5 \mathrm{n} M)$ was selected for the field experiments. Cultures from the selected colony were maintained in sterile Marine Broth 2216 (Difco) supplemented with $50 \mu \mathrm{g} \mathrm{mL}^{-1}$ of Tc at $25^{\circ} \mathrm{C}$ in sterile $50-\mathrm{mL}$ polycarbonate tubes on an orbital shaker. Pre-acclimation of the bioreporter cells prior to experiments was performed in BESAW, a completely defined medium modified from the Enriched Seawater/Artificial water recipe (ESAW [Berges et al., 2001]) and optimized for heterotrophic bacteria growth (Table 1). Final free ferric ion concentrations (expressed as both $\mathrm{pFe}$, the $-\log \left[\mathrm{Fe}^{3+}\right]$, and $\mathrm{Fe}(\mathrm{III})^{\prime}$, the sum of the inorganic $\mathrm{Fe}^{3+}$ species) as well as the concentration of other free trace metals were inferred using the chemical equilibrium software MINEQL+ ver.4.06 (Table 2). To reduce residual Fe, all nutrient stocks and water were treated with Chelex-100 resin [Price et al., 1988/1989]. All culture materials were soaked in dilute $\mathrm{HCl}$ 
Table 2. Total Concentrations of Trace Metals Added to BESAW Medium ( $\mathrm{pH}$ 7.8) With an EDTA Concentration of $100 \mu \mathrm{M}$ and Correspondence to Free Metal Ion Concentrations for Each Treatment as Computed Using the Chemical Equilibrium Program MINEQL

\begin{tabular}{lccccccc}
\hline$[\mathrm{Fe}], M$ & $\mathrm{EDTA}, M$ & {$\left[\mathrm{Fe}^{3+}\right], M$} & $\mathrm{Fe}(\mathrm{III})^{\prime}$ & $\mathrm{pFe}$ & $\mathrm{pZn}$ & $\mathrm{pCo}$ & $\mathrm{pMn}$ \\
\hline $5 \times 10^{-9}$ & $10^{-4}$ & $10^{-21.15}$ & 0.9 & 21.2 & 9.38 & 11.2 & 6.12 \\
$5 \times 10^{-8}$ & $10^{-4}$ & $10^{-20.15}$ & 9.3 & 20.2 & 9.38 & 11.2 & 6.19 \\
$2 \times 10^{-7}$ & $10^{-4}$ & $10^{-19.54}$ & 37 & 19.5 & 9.38 & 11.2 & 13.1 \\
$5 \times 10^{-7}$ & $10^{-4}$ & $10^{-19.14}$ & 93 & 19.1 & 9.38 & 11.2 & 6.18 \\
$7.5 \times 10^{-7}$ & $10^{-4}$ & $10^{-18.97}$ & 140 & 19.0 & 9.38 & 11.2 & 6.18 \\
$5 \times 10^{-6}$ & $10^{-4}$ & $10^{-18.12}$ & 980 & 18.1 & 9.36 & 11.2 & 6.17 \\
$5 \times 10^{-5}$ & $10^{-4}$ & $10^{-16.84}$ & $1.8 \times 10^{4} \mathrm{a}$ & 16.8 & 9.09 & 13.1 & 13.1 \\
\hline
\end{tabular}

${ }^{\mathrm{a}} \mathrm{Fe}$ concentrations at this level will lead to Fe precipitation within the medium.

(5\%) and rinsed with Chelex-100 treated Milli-Q water and culture vessels were microwave-sterilized prior to use. All manipulations were performed under a class-100 laminar flow hood using aseptic and trace-metal clean techniques.

\subsection{Laboratory Characterization of $P$. putida FeLux as Fe-Dependent Bioreporter}

[6] Reagents and medium for the characterization of the bioreporter were prepared prior to the day of the experiment. Sterile aliquots of Fe-free BESAW $(18 \mathrm{~mL})$ were dispensed into polycarbonate Oakridge tubes (Nalgene) and supplemented with $\mathrm{Fe}$ from an Fe:EDTA concentrated stock. The concentration of $\mathrm{FeCl}_{3} \bullet 6 \mathrm{H}_{2} \mathrm{O}$ was altered in each premix to create an increasing range of bioavailable Fe. The final concentration of EDTA was maintained constant $(100 \mu M)$ for all treatments. For pre-acclimation, $5 \mathrm{~mL}$ of culture grown in Marine Broth 2216 (Difco) was transferred to a $500-\mathrm{mL}$ polycarbonate Erlenmeyer flask containing $95 \mathrm{~mL}$ of sterile, Fe-deficient BESAW (pFe 21.2, Table 2) and incubated overnight in the dark at $25^{\circ} \mathrm{C}$ with shaking. The experiment was initiated by transferring $2 \mathrm{~mL}$ this culture to each replicate tube ( $n=3$ for each treatment). The optical density at $600 \mathrm{~nm}\left(\mathrm{OD}_{600}\right)$ and light production were measured at 2-hour intervals over an experimental period of 12 hours using a spectrophotometer (Biomate 5, Thermospectronic corp.) and luminometer (FB-15, Zylux Corp.). Samples in the luminometer were measured after a 1-s delay period with a 5-s integration time and blank subtraction. The sensitivity of the FB-15 PMT is 1000 luciferase molecules per reaction (manufacturer's specifications). For each time point, light production was normalized to $\mathrm{OD}_{600}$. The results of the experiment are expressed as light levels at different $\mathrm{pFe}$ (or Fe(III)') equivalents. This allows for the characterization of Fe in different chemically modified media and comparison (using the calibrated BESAW response as a standard) between samples and systems.

[7] In a separate experiment, Fe-replete bioreporter cultures were used to calibrate the $\mathrm{OD}_{600}$ value to cell concentration. Cells were preconditioned as described above and transferred to BESAW medium of $\mathrm{pFe}$ 18.1. At 2-hour intervals, cells were sampled to measure the luminescence and optical density at $600 \mathrm{~nm}$ (Figure 1a). In parallel, $1 \mathrm{~mL}$ of culture was fixed with glutaraldehyde $(2.5 \% \mathrm{v} / \mathrm{v})$ and enumerated by epifluorescence microscopy after treatment with acridine orange [Hobbie et al., 1977]. Since the $\mathrm{OD}_{600}$ values correlated strongly $\left(R^{2}=0.988\right)$ with the density of bioreporter cells (Figure 1b), light production normalized to $\mathrm{OD}_{600}$ was converted to light emitted per reporter cell using the empirically determined linear function,

$$
y=3.61 \times 10^{8} x-3.46 \times 10^{6},
$$

where $y$ is the concentration of bioreporter cells $\mathrm{mL}^{-1}$ and $x$ is the corresponding $\mathrm{OD}_{600}$ value. Reported values are the
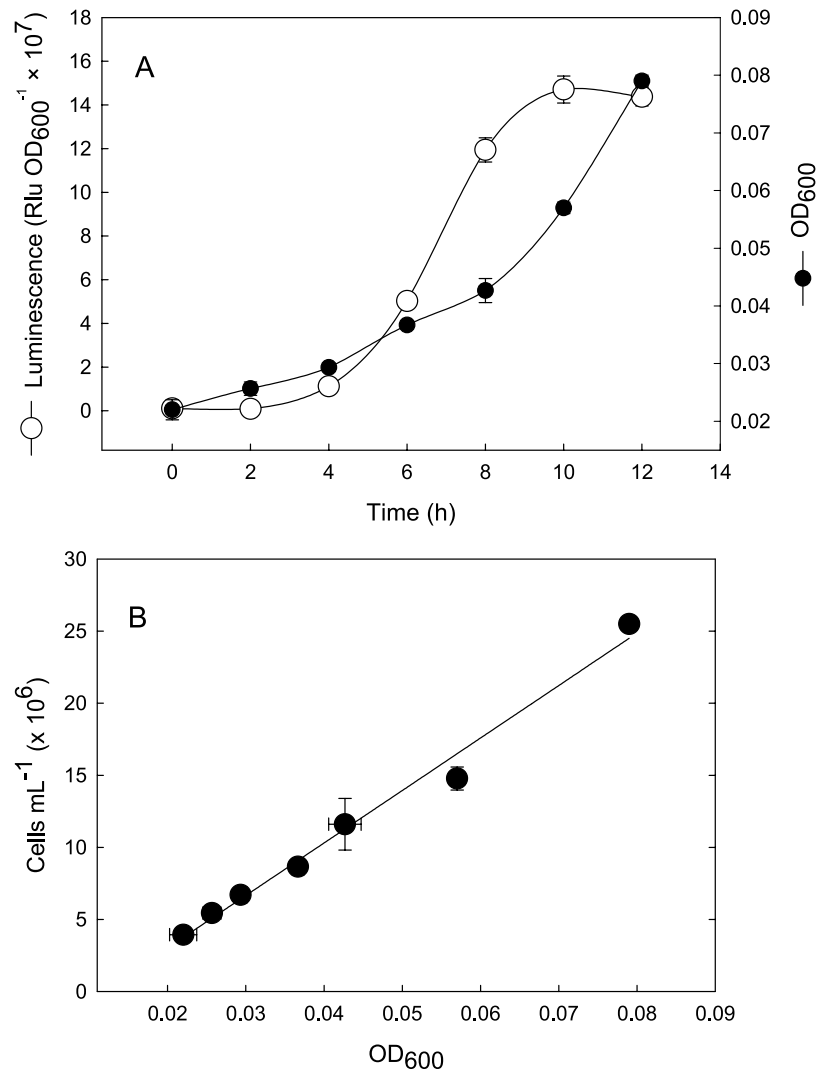

Figure 1. Laboratory characterization of the $P$. putida FeLux bioreporter in the trace metal buffered BESAW medium. (a) Typical growth curve and light production (Rlu: relative luminescence units) of $P$. putida FeLux in BESAW medium (pFe 18.1). Error bars represent the standard deviation between triplicates when larger than the symbol. (b) Typical calibration curve of $\mathrm{OD}_{600}$ and cell concentration in Fe-replete BESAW medium with resulting linearization $\left(R^{2}=0.988\right.$; slope $=3.61 \times 10^{8}, y$ intercept $=$ $\left.-3.46 \times 10^{6}\right)$. Error bars represent the standard deviations of triplicates when larger than the symbol size. 
means of triplicate cultures $( \pm$ S.D. $)$ from the time-point for which the signal was the strongest ( $t=12$ hours). Owing to the high reproducibility of the data, calibration data will be presented here as the mean of the data obtained from three experiments performed in identical conditions $(n=9$ per treatment).

\subsection{Site Selection and Survey}

[8] The FeCycle mesoscale experiment was designed to develop an unperturbed Fe budget by following a patch of surface water in a $\mathrm{HNLC}$ region labeled with $\mathrm{SF}_{6}$ as a tracer [see Boyd et al., 2005]. The study site was previously characterized by subpolar high nutrient-low silicic acidlow chlorophyll [HNLSiLC; Dugdale and Wilkerson, 1998] waters that are representative of the majority of the Southern Ocean surface waters ( $65 \%$ [Coale et al., 2004]). During austral summer in this region, surface waters are typically depleted $(<1 \mu M)$ of silicic acid $\left(\mathrm{Si}(\mathrm{OH})_{4}\right)$ as well as Fe; indeed it has been suggested that diatom stocks remain low due to a $\mathrm{Si}(\mathrm{OH})_{4}-\mathrm{Fe}$ co-limitation [Boyd et al., 2001; Hutchins et al., 2001b]. The austral summer provides optimal conditions to study possible mechanisms that control HNLC assemblages as during this period of the year the HNLSiLC community is dominated by prokaryotic and picoeukaryotic organisms [Boyd et al., 2001, 2005; Hutchins et al., 2001b].

[9] The FeCycle mesoscale experiment was conducted during late austral summer (30 January 2003 to 12 February $2003)$ in the vicinity of the NIWA's Southern mooring site ( $\left.\sim 46^{\circ} 30 \mathrm{~S}, 178^{\circ} 30 \mathrm{E}\right)$ on board of the RV Tangaroa. The study site location was selected based on a pre-release oceanographic survey (circa XTB section, CTD and underway seawater sampling) and local remote sensing (SeaWiFS, SSH, SST, mooring data) as described by Boyd et al. [2005]. Once the study site was selected, surface waters were labeled over a $47-\mathrm{km}^{2}$ area using the chemically inert tracer sulfur hexafluoride $\left(\mathrm{SF}_{6}\right)$ in a manner similar to that used during the SOIREE voyage [Boyd et al., 2000; Bowie et al., 2001]. However, unlike the SOIREE experiment, the labeled patch was not infused with Fe. $\mathrm{SF}_{6}$ concentrations were analyzed during daily underway mapping of the patch as described elsewhere in this special section [Boyd et al., 2005].

\subsection{Field Sample Collection}

[10] All samples for Fe bioreporter analysis were collected at the center of the $\mathrm{SF}_{6}$-labeled patch using a trace-metal clean pumping system (Almatec) as described in a related paper [McKay et al., 2005]. Waters were homogenized in an acid-cleaned container and subsequently filtered $(0.2 \mu \mathrm{m})$, collected in an acid-cleaned polycarbonate flasks and stored frozen $\left(-20^{\circ} \mathrm{C}\right)$ until use. Samples were collected prior to sunrise ( $\sim$ 5:00 local time) from a depth of approximately 5$7 \mathrm{~m}$.

[11] Seawater samples for Fe chemistry were also concurrently collected using the trace metal clean pumping system. Total dissolved Fe concentrations (DFe, $<0.2 \mu \mathrm{m}$ ) were determined on samples using a combination of the solvent extraction techniques described by Danielsson et al. [1978] and Bruland et al. [1979]. Briefly, $250 \mathrm{~g}$ of seawater was buffered to a $\mathrm{pH}$ of 4.5 with purified ammonium acetate buffer in a $250-\mathrm{mL}$ Teflon separation funnel. Purified ammonium pyrrolidine-dithiocarbamate (APDC)/sodium diethyl-dithiocarbamate (DDC) solution was then added followed by $5 \mathrm{~mL}$ of cleaned chloroform. The sample was extracted by shaking for $3 \mathrm{~min}$. After allowing the phases to separate, chloroform was drained and the sample extracted a second time with $5 \mathrm{~mL}$ of chloroform. Following extraction, chloroform primary and secondary extracts were pooled, acidified with $75 \mathrm{~mL}$ of Teflon-distilled $\mathrm{HNO}_{3}\left(\mathrm{t}-\mathrm{HNO}_{3}\right)$, shaken, and left to react for 1 hour. Metals back-extracted from the chloroform phase were diluted to $1 \mathrm{~mL}$ with Nanopure water, shaken, and left overnight before analysis by graphite furnace atomic adsorption spectrometry using a Perkin-Elmer 4100 ZL with Zeeman background correction.

[12] As a proxy for phytoplankton biomass in the water column total chlorophyll $a(\operatorname{chl} a)$ was determined from duplicate $50-\mathrm{mL}$ samples collected on $0.2-\mu \mathrm{m}$ pore size polycarbonate filters (Osmonics) after extraction ( $\sim 24$ hours) in 90\% acetone. Chl $a$ was quantified with a Turner Designs TD-700 fluorometer using the nonacidification protocol of Welschmeyer [1994].

\subsection{Determination of in Situ Fe Bioavailability to the Bacterial Bioreporter}

[13] Preacclimated P. putida FeLux bioreporter cells (BESAW medium, pFe 21.2) were used to estimate bioavailable $\mathrm{Fe}$ in the seawater samples obtained during FeCycle. The following Chelex-100 treated (except vitamins) and filter-sterilized nutrient stocks were added to filtered $(0.2-\mu \mathrm{m})$ seawater samples to ensure that the level of all nutrients except Fe were sufficient to support the growth of the bioreporters: $20 \mu M \mathrm{NH}_{4} \mathrm{NO}_{3}, 10 \mu M$ $\mathrm{NaH}_{2} \mathrm{PO}_{4}, 1 \mu M$ glycerol, and $100 \mu \mathrm{L}$ vitamin mix (ESAW vitamins recipe [Berges et al., 2001]). Enriched seawater $(18 \mathrm{~mL})$ was dispensed into Oak-ridge tubes. Triplicate samples were either unaltered (control treatment) or supplemented with $\mathrm{FeCl}_{3}$ (1.5 $\mathrm{n} M$ final concentration). Amendment of the seawater samples was performed at least 24 hours before the addition of preconditioned bioreporter cells. At time zero, $2 \mathrm{~mL}$ of pre-acclimated $P$. putida FeLux bioreporter cells were added to each replicate. $\mathrm{OD}_{600}$ and light production were measured at 2-hour intervals over a period of 12 hours using a spectrophotometer (Biomate 5, Thermospectronic corp.) and a luminometer (FB-15, Zylux corp.). At each time point, light production was normalized to $\mathrm{OD}_{600}$ and then converted to light production per reporter cell. Bioavailable Fe levels (estimated as Fe(III)', which equals the sum of the inorganic Fe species) were predicted from estimated cellular luminescence using the calibration curve established from BESAW medium treatments with known $\mathrm{pFe}$. Calibration treatments were run in parallel to seawater treatments for each experiment.

\subsection{Statistical Analyses}

[14] Statistical analyses for all data were performed using SPSS (version 12) software. Analyses of variance and independent $t$-tests (two-tailed) were performed assuming equal variance on mean values. The homogeneity of variance was tested in each analysis using the Levene test. For 


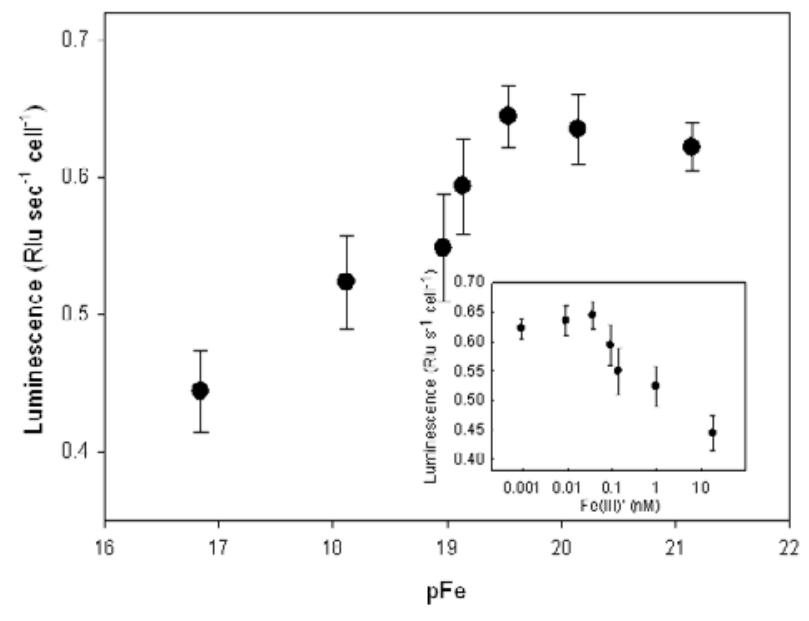

Figure 2. Dose-response characterization of the $\mathrm{Fe}$ bioreporter $P$. putida FeLux in the trace metal buffered BESAW medium. Cells preconditioned in Fe-deficient BESAW $\left(\mathrm{Fe}^{3+}=10^{-21.2} M\right)$ were inoculated in BESAW medium at various free ferric iron concentrations $\left(\mathrm{Fe}^{3+}=\right.$ $10^{-21.2} \mathrm{M}, 10^{-20.2} \mathrm{M}, 10^{-19.5} \mathrm{M}, 10^{-19.1} \mathrm{M}, 10^{-19.0} \mathrm{M}$, $10^{-18.1} M, 10^{-16.8} M$ ). Bioluminescence was measured following 12 hours of incubation and normalized to the number of bioreporter cells $\mathrm{mL}^{-1}$. Values reported represent the average value obtained for three experiments performed in identical conditions. Error bars represent the standard deviations of three experiments with triplicate samples analyzed in each experiment $(n=9)$. Regression analysis of the linear range pFe $16.8\left(\mathrm{Fe}^{3+}=10^{-16.8} M\right)$ to $\mathrm{pFe} 19.6$ $\left(\mathrm{Fe}^{3+}=10^{-19.6} M\right)$ is shown $\left(R^{2}=0.935\right.$; slope $=0.070$ and $\mathrm{y}$ intercept $=-0.684)$.

incubation experiments, analysis of variance (one-way ANOVA) was used to establish the statistical significances of variation among different treatments. In parallel, multiple comparison tests were performed to determine where the differences lay. Dunnett's test was used to analyze the significance of the variations of the means of a set of amended treatments relative to the control treatment mean [Corston and Colman, 2003]. The Tukey's honestly significant difference test (Tukey-HSD test) was used to establish the statistical significance of variations among a set of treatments means [Corston and Colman, 2003]. For all analyses, a 95\% confidence interval was used. Results were considered significant at $p<0.05$ unless otherwise stated.

\section{Results}

\subsection{Laboratory Characterization}

[15] To characterize the response of the bioreporter to $\mathrm{Fe}$ bioavailability, preconditioned $P$. putida FeLux cells were incubated for 12 hours in the trace-metal buffered synthetic seawater medium BESAW supplemented with various concentrations of $\mathrm{Fe}$ to obtain a calculated range of $\mathrm{pFe} 21.2$ $($ an $\mathrm{Fe}(\mathrm{III})=0.9 \mathrm{p} M)$ to $\mathrm{pFe} 16.8\left(\right.$ an $\left.\mathrm{Fe}(\mathrm{III})^{\prime}=180 \mathrm{nM}\right)$ (Figure 2). The Fe-chelating agent EDTA was used to buffer $\mathrm{Fe}^{3+}$ concentrations in BESAW culture medium. It has previously been demonstrated that unlike other common xenobiotic ligands such as nitriloacetic acid (NTA), EDTA does not promote intracellular Fe incorporation in Pseudomonas species [Meyer and Hohnabel, 1992]. The use of this Fe chelating-agent ensured therefore that the bioluminescence signal could be related to the bioavailable $\mathrm{Fe}$ in the environment of the bioreporter cells. For the purpose of comparison between systems, the pFe of our model medium was used as metric to gauge Fe chemistry. Similar calculations (e.g., the sum of the inorganic Fe species, $\mathrm{Fe}^{\prime}$ ) can also be made for the defined medium. Bioluminescence increased linearly between treatment $\mathrm{pFe}$ 16.8 and $\mathrm{pFe} 19.5$, and reached a maximum for lower total Fe concentrations. All environmental samples tested were within the linear range of the calibration curve. A linear regression performed using the regression curve fitting of the Sigma Plot software (version 9.0, SPSS corporation) in the linear region of this calibration curve provided the following equation $\left(R^{2}=0.935\right)$ :

$$
y=0.0701 x-0.684
$$

where, $y=$ luminescence per second per cell, and $x=\mathrm{pFe}$.

\subsection{Background Conditions at the FeCycle Study Site}

\subsubsection{Dissolved Fe Concentrations in the Patch}

[16] The FeCycle site had a surface mixed layer of $\sim 40$ $50 \mathrm{~m}$ [Ellwood, 2004] characteristic of Austral summer thermal stratification in this region [Hutchins et al., 2001b; Boyd et al., 2001]. Concentrations of DFe at the patch center by the graphite furnace technique were low $(<0.075 \mathrm{nM})$ for samples from surface waters throughout the study period (Figure 3 ). The initial vertical profile (5 February 2003) showed a minimum of $0.043 \mathrm{n} M$ Fe at a depth of $32 \mathrm{~m}$. Independent estimates of DFe concentrations from flow injection analysis provided different results and are discussed elsewhere (P. L. Croot et al., The effects of physical forcing on iron chemistry and speciation during the FeCycle experiment in the south West Pacific, submitted to Global Biogeochemical Cycles, 2005) (here-

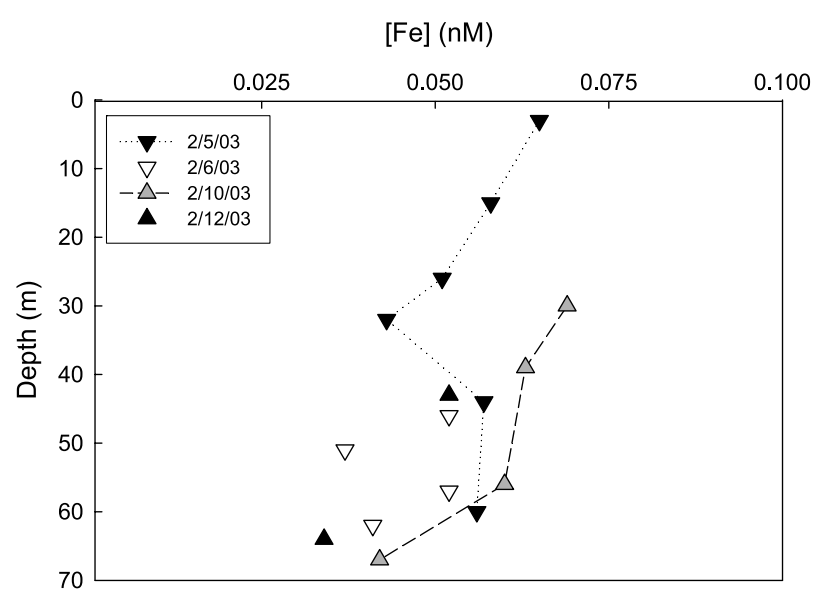

Figure 3. Depth profiles of total dissolved $\mathrm{Fe}(<0.2 \mu \mathrm{m}, \mathrm{n} M)$ concentrations determined at four stations located at the center of the $\mathrm{SF}_{6}$-labeled patch. 

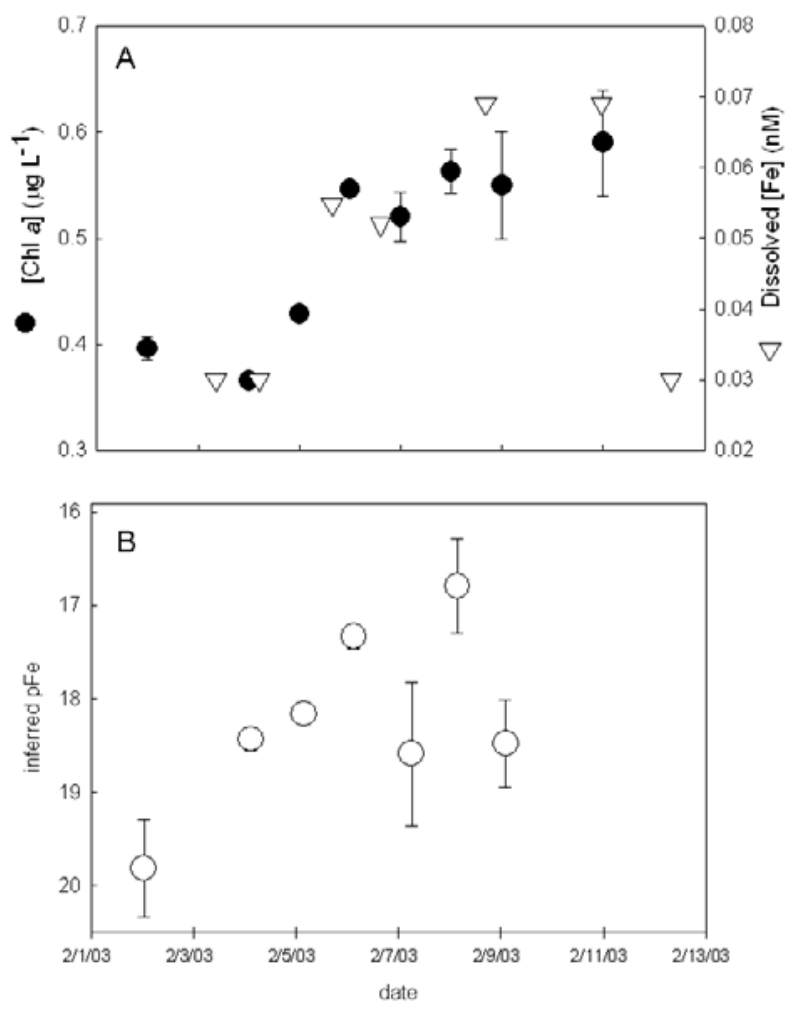

Figure 4. Comparison of changes in dissolved $\mathrm{Fe}$ concentration, Chl $a$ and Fe bioavailability within the mixed layer of $\mathrm{SF}_{6}$-labeled waters. (a) Dissolved Fe (open triangles, $\mathrm{n} M$ ) and $\mathrm{Chl} a$ (solid circles, $\mu \mathrm{g} \mathrm{L}^{-1}$ ) concentrations within the FeCycle patch. (b) Bioavailable Fe level (estimated as $\mathrm{pFe}=-\log \left[\mathrm{Fe}^{3+}\right]$ ) predicted from $P$. putida bioreporter cells luminescence analyses(open circles). Cells preconditioned in Fe-deficient BESAW medium were used to inoculate seawater samples. Luminescence values normalized by cell density (cell $\mathrm{mL}^{-1}$ ) were used to estimate the corresponding $\mathrm{pFe}$ based on the calibration curve obtained in the trace metal buffered BESAW medium. Error bars represent the standard deviations between replicates $(n=3)$.

inafter referred to as Croot et al., submitted manuscript, 2005).

[17] Within the mixed layer of the $\mathrm{SF}_{6}$-labeled patch, initial DFe concentrations were very low (0.030 $\mathrm{n} M$; Figure $4 \mathrm{a})$. The DFe concentration doubled from 4 to 8 February, and reached a maximum of 0.069 . It remained at that value until 10 February and then decreased to $0.03 \mathrm{n} M$ on 12 February. These fluctuations in DFe concentrations are hypothesized to be driven by the entrainment of surrounding HNLC waters which different Fe concentrations (Croot et al., submitted manuscript, 2005) and chl $a$ [Boyd et al., 2005]. In part this entrainment resulted from the increase in the areal extent of the patch (from 70 to $>400 \mathrm{~km}^{2}$ ) over 10 days (Croot et al., submitted manuscript, 2005). The end results of these fluctuations in DFe concentrations provided a "natural laboratory" in which to rigorously test the Fe bioreporter.

\subsubsection{Total Chlorophyll $a$}

[18] Low DFe concentrations coincided with low initial chl $a$ concentrations $\left(<0.40 \mu \mathrm{g} \mathrm{L}^{-1}\right)$ in the mixed layer during FeCycle (Figure 4a). No change in chl a was observed during the two first days of the study. Total community chl a concentration increases $(\sim 60 \%)$ were concomitant with the increase in DFe observed between 4 and 6 February. These concentrations remained around $0.55 \pm 0.02 \mu \mathrm{g} \mathrm{L}^{-1}$ for the rest of the study period, suggesting that the increase in dissolved Fe concentration ( $0.040 \mathrm{n} M$ ) may have been due to the entrainment of surrounding waters containing higher DFe and chlorophyll concentrations or that entrained DFe might have stimulated a modest increase in total chl $a$.

\subsection{Assessment of Fe Bioavailability Over the Course of the FeCycle Voyage}

[19] Relative bioavailable Fe levels (estimated from the response of the bioreporter in a standard, $\mathrm{pFe}$ defined medium) in the dissolved fraction $(<0.2 \mu \mathrm{m})$ of surface seawater predicted from the $P$. putida FeLux bioluminescent reporter are represented on Figure 4b. Initial bioavailable Fe (2 February 2004) was lower than in the Fe-replete pFe 16.8 medium as bioreporters produced light levels equivalent to the highest concentrations of $\mathrm{Fe}$ on the calibration curve, suggesting that high-affinity Fe transport systems of $P$. putida FeLux cells were fully repressed. On the basis of bioluminescent reporter analyses, the evolution of $\mathrm{Fe}$ bioavailability over the study period can be divided in two main phases. Between 2 and 6 February, as dissolved $\mathrm{Fe}$ in surface water increased, inferred pFe decreased significantly $(\mathrm{p}<0.05)$ and in a log linear fashion $\left(R^{2}=\right.$ $0.99)$, dropping to a minimal $\mathrm{pFe}$ value of $\sim 17.4 \pm 0.9$. This observation suggests that the transient increases in dissolved $\mathrm{Fe}$ in the surface water were sufficient to be sensed (vis a vis altering the intracellular Fe status) by $P$. putida FeLux and to allow for the repression of highaffinity $\mathrm{Fe}$ transports. Dissolved $\mathrm{Fe}$ concentrations in surface waters were $\sim 0.06 \mathrm{n} M$ from 6 to 8 February (Figure 4a). Analysis of this water with the bioreporter provided results comparable to $\mathrm{pFe} 16.8-18.5$ in our model medium (Figure 4b), suggesting that sufficient Fe was available for growth. On 9 February, Fe bioavailability decreased to the estimated levels of 4 February, indicative of a slight decrease in DFe, (although DFe concentrations were not determined at this time point). With the exception of the 7 February samples, the results suggest a strong correlation between the total $\mathrm{DFe}$ pool and the bioavailable $\mathrm{Fe}$ pool.

[20] Addition of $1.5 \mathrm{n} M$ of Fe to seawater sampled when Fe concentrations peaked $(\sim 0.069 \mathrm{n} M)$ within the patch resulted in significantly lower luminescence ( $t$-test, $p<$ $0.05)$ which is characteristic of Fe-replete bacterial cells (Figure 5). This result suggests that although bioreporter cells sensed an increase in bioavailable $\mathrm{Fe}$ in the surface seawater, their high-affinity transport systems were never completely repressed. The decrease in luminescence in Fe-amended relative to unamended treatments was of comparable magnitude for the three samples examined, averaging $0.19 \pm 0.02$ relative light units $\mathrm{s}^{-1}$ cell ${ }^{-1}$. Not only does this data demonstrate the reproducibility of the 


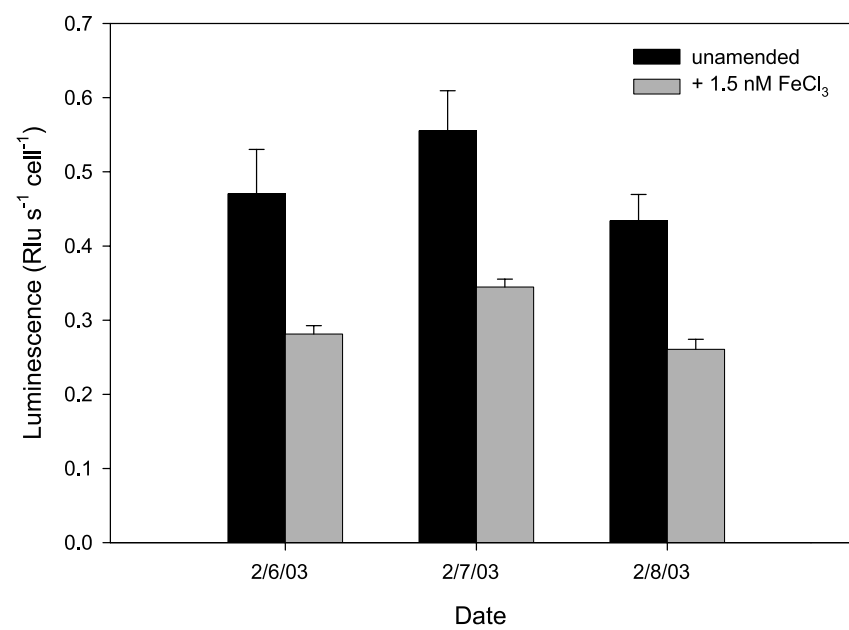

Figure 5. Influence of added $\mathrm{FeCl}_{3}$ on perceived $\mathrm{Fe}$ bioavailability. Luminescence measures from bioreporter cells grown in $0.2-\mu \mathrm{m}$ filtered surface water and Fe $(1.5 \mathrm{n} M)$ amended $0.2-\mu \mathrm{m}$ filtered surface water from the center of the FeCycle patch for 6 through 8 February. Although Fe concentrations and Fe bioavailability peaked during this period, the results indicate that high-affinity transporters could still be further suppressed by added Fe, and as such the Fe availability was still in part constraining the community.

response of the bioreporter cells, it also demonstrates that the dynamic range of bioreporter response is well within the natural variation in $\mathrm{Fe}$ concentrations that can be observed in HNLC systems.

\section{Discussion}

\subsection{Information Provided by the Fe-Dependent Heterotrophic Bioreporter}

[21] This article is the first to describe the use of a prokaryotic Fe-specific bioluminescent reporter in seawater to directly estimate Fe bioavailability to heterotrophic bacteria. The use of $P$. putida FeLux strain as a diagnostic tool of Fe bioavailability presents several advantages. First, the regulation of $\mathrm{Fe}$ metabolism in response to $\mathrm{Fe}$ availability via the ferric-uptake regulator protein (FUR) is widespread among marine, freshwater, terrestrial, commensal and pathogenic heterotrophic bacterial strains [Escolar et al., 1999; Andrews et al., 2003]. Indeed, for pathogenic bacteria one of the most difficult parts of infecting a new host is scavenging Fe, which they accomplish using mechanisms similar to the one bacteria employ in seawater [Wilhelm, 1995; Weinberg, 1998]. And while we have no doubt that there are other potential Fe transport systems in marine environments, the FUR system is indeed among the most prominent; a BLAST analysis of the Sargasso Sea shotgun library [Venter et al., 2004] demonstrates more than 100 quality hits to the FUR protein of E. coli (data not shown), implying it is well distributed within this marine system. As such, this transport system is representative of many $\mathrm{Fe}$ transport systems in the ocean. Moreover, while specific bacteria may assimilate Fe from different Fe-organic pools and respond to Fe stress by producing different siderophores [Wilhelm, 1995], the regulation of this process within the majority of well-characterized microbial cells is by the FUR system, and as such conserved. Therefore bioreporters based on the FUR-regulated fepA-fes promoter fusion are an appropriate tool to estimate the Fe-status of many members of the heterotrophic bacterial component in environments such as seawater.

[22] Second, owing to the halotolerance of $P$. putida FeLux, this strain can be used to detect Fe bioavailability in a wide range of environments (e.g., along a salinity gradient). Previously, this bioreporter had been employed to determine $\mathrm{Fe}$ availability in a freshwater system (Lake Erie) and to elucidate the impact of various $\mathrm{Fe}$ chelators in freshwater culture medium [Mioni et al., 2003]. In this study, we have demonstrated the applicability of this bioreporter to open ocean HNLC waters where heterotrophic bacteria play a dominant role in both $\mathrm{Fe}$ uptake and in $\mathrm{Fe}$ regeneration via virus-mediated lysis and/or grazing of bacterial cells [Strzepek et al., 2005]. Using this bioreporter strain and an incubation time of 12 hours in a synthetic seawater medium, the bioluminescent reporter cells responded to increasing bioavailable Fe in a dose dependent manner within the range of $\mathrm{pFe}$ values of 19.5 to 16.8 . Although these values may appear relatively high, results from water samples collected within the FeCycle patch fell within the linear portion of our calibration curve, allowing us to estimate corresponding bioavailable Fe levels. Furthermore, the results indicate that our bacterial reporter was sensitive enough to detect subnanomolar changes in bioavailable $\mathrm{Fe}$ in this environment. Effectively, a transient increase of $\sim 0.040 \mathrm{n} M$ Fe was sufficient to increase Fe bioavailability to the $P$. putida FeLux reporter strain.

[23] The data also suggest that this strain can provide insight regarding the relationship between bioavailable Fe and total DFe concentrations. During the transient increase in total dissolved Fe (2-6 February), if the character of the Fe-organic complexes also changed (e.g., as new organically complexed Fe was entrained), they were at least partially available to $P$. putida FeLux since inferred bioavailable Fe levels tracked the changes in DFe concentrations within the SF6 labeled patch. Although, using a single strain of bacteria should be cautiously extrapolated to the natural populations (as Fe requirements and uptake of alternate substrates vary between species), the data suggest that the transient increase in dissolved Fe may have been sufficient to stimulate production by the prokaryotic component of the microbial community. It is important to note that the calibrations values are valid against the standard medium only, and not predictions of Fe speciation (e.g., $\left.\mathrm{pFe}, \mathrm{Fe}(\mathrm{III})^{\prime}\right)$. The importance of these values is that the response at these concentrations is highly reproducible, and as such they can serve as a relative comparison at different locations and across different times.

\subsection{Comparing the Response of Bacteria and Algae to Changes in DFe During FeCycle}

[24] In contrast to our indicator of the heterotrophic bacterial Fe-status, the response of the resident phytoplank- 
ton assemblage to fluctuations in dissolved $\mathrm{Fe}$ concentrations during FeCycle was not evident. Although chl $a$ concentrations increased over time in the patch (potentially due to entrainment of phytoplankton or in response to the elevated $\mathrm{Fe}$ concentration), photosynthetic efficiencies remained low $\left(\mathrm{F}_{\mathrm{v}} / \mathrm{F}_{\mathrm{m}} \sim 0.2 ;[\right.$ McKay et al., 2005]). Moreover, the Ferredoxin Index (the ferredoxin to flavodoxin ratio in plankton) ranged from 0.07 to 0.25 over the course of FeCycle, again suggesting that a strong physiological Fe-limitation (typically denoted by ratios $<0.5$ [Strzepek and Harrison, 2004]) prevailed in the resident phytoplankton community [McKay et al., 2005]. Several scenarios could explain this disparity between the responses of photosynthetic plankton community and the heterotrophic reporter to the transient Fe increase: (1) Fe from entrained waters was rapidly complexed by prokaryotic siderophores, making it unavailable to phytoplankton but potentially available to the bioreporter; (2) the speciation of the entrained Fe may have been more bioavailable to the bacterioplankton than phytoplankton, resulting in a stronger physiological limitation of the photosynthetic assemblage relative to the heterotrophic bacterium; (3) the entrained water may have introduced a different plankton population that biologically altered the system's Fe chemistry; and (4) the different approaches employed here to assess Fe stress may yield to differing sensitivities. Indeed, the algal photosynthetic competence $\left(\mathrm{F}_{\mathrm{v}} / \mathrm{F}_{\mathrm{m}}\right)$ and Ferredoxin ratio approaches may not be as sensitive to increases in $\mathrm{Fe}$ bioavailability. Although we are unable to resolve the differences observed between the heterotrophic bioreporter and the proxies for phytoplankton Fe-status [see McKay et al., 2005], our bioreporter data demonstrate an increase in Fe bioavailability concurrent to a subnanomolar increase in dissolved $\mathrm{Fe}$ concentrations.

[25] One parameter not considered in the above information is the potential for $\mathrm{Fe}$ to have been shunted from the particulate $\mathrm{Fe}$ pool to the dissolved $\mathrm{Fe}$ pool during our observations. The abundant cyanobacterial and heterotrophic prokaryote populations in the FeCycle patch [Strzepek et al., 2005] represented a significant pool of particulate $\mathrm{Fe}$. Recent studies suggest that the virus-mediated lysis of prokaryotes can lead to a release of significant organically complexed Fe [Wilhelm and Suttle, 1999; Poorvin et al., 2004]. Indeed, when taken in light of the companion studies and previous work cited above, our results suggest that Fe-ligand complexes present in the surface waters of the patch (derived from viral-mediated lysis, grazing byproducts and/or siderophore production) were available to our bioreporter but may not have been available to eukaryotic phytoplankton.

\subsection{Significance at the Ecosystem Level}

[26] The current tenets of oceanography assume that picoplankton dominate HNLC areas because they are less physiologically limited by Fe availability than large phytoplankton species such as diatoms [Sunda and Huntsman, 1997; Price et al., 1994] or, in many cases, because they maintain high-affinity transport systems [Wilhelm and Trick, 1994]. However, diagnostic probes/indices currently available have so far failed to confirm this hypothesis and instead have suggested that the resident picoplankton-dominated community is also Fe-limited [Greene et al., 1994]. The majority of diagnostic markers for environmentally imposed stress are generally optimized for, or specific to, the photosynthetic and mostly eukaryotic component of HNLC assemblages [Beardall et al., 2001; Firme et al., 2003]. At this time, no other diagnostic marker specific to heterotrophic bacteria is available. The heterotrophic bioluminescent reporter represents the first diagnostic tool specifically optimized to estimate the degree of Fe limitation of a component of the marine heterotrophic community.

[27] If we cautiously assume the sensitivity of the indigenous heterotrophic bacteria in HNLC waters is represented by the bioreporter, then we can extrapolate and conclude that the heterotrophic bacterial community responded differently than the phytoplankton community during the subtle shift in DFe supply that occurred during FeCycle (i.e., the $\mathrm{Fe}$ was more bioavailable to the bacteria than to the phytoplankton). The data presented here further suggest that the heterotrophic bioreporter is differentially sensitive (relative to the photosynthetic plankton) to natural variations in $\mathrm{Fe}$ bioavailability. Although the heterotrophic bioreporter and the phytoplankton (as diagnosed by both $\mathrm{F}_{\mathrm{v}} / \mathrm{F}_{\mathrm{m}}$ and the ferredoxin diagnostic index [McKay et al., 2005] were Fe-limited at the beginning of the survey, only the bioreporter bacterial cells demonstrated a relaxation of their Fe-limited state during the transient elevation in $\mathrm{Fe}$ availability. Moreover, our bioluminescent reporter suggested that $1.5-\mathrm{n} M$ Fe amendments of the seawater samples completely alleviated Fe-limitation in the heterotrophic bacteria, while comparable $\mathrm{Fe}$ amendments to on-deck incubation experiments, while resulting in enhanced chl $a$ production, were not sufficient to completely alleviate nutrient stress of resident phytoplankton cells (as reflected by $\mathrm{F}_{\mathrm{v}} / \mathrm{F}_{\mathrm{m}}$ values below the theoretical maximum of $\sim 0.65$ [McKay et al., 2005]).

\section{Conclusions}

[28] This work has explored the use of bioreporters as a novel and sensitive biotechnology tool to estimate the bioavailability of $\mathrm{Fe}$ in marine environments; indeed, experiments concerning microbial $\mathrm{Fe}$ assimilation and bioavailability have been suggested as critical future needs by recent international working groups [SOLAS, 2005]. At this time, no other diagnostic marker of Fe availability specific to the heterotrophic bacterial community is available. By employing this tool we have generated data that suggest that small changes in total dissolved Fe concentrations, at the limit of chemical detection, could result in significant changes to the bioavailable $\mathrm{Fe}$ pool and thereby induce important changes in the microbial food web. Although such small-scale experiments need to be interpreted with caution, and constructus need to be introduced into more marine "relevant" bacteria, these results have important implications for the study of the biogeochemical cycling of Fe as they demonstrate that heterotrophic bacteria are key players in the "microbial ferrous wheel" [Kirchman, 1996].

[29] Acknowledgments. The authors thank Russell Frew, Julie Hall, Clint Hare, Julie Higgins, David Hutchins, Cliff Law, Stuart Pickmere, and 
the captain and crew of R/V Tangaroa for assistance in sample collection. The authors also thank Gary Sayler, Paul Tréguer, Bill Sunda, and an anonymous reviewer for valuable comments during the preparation of the manuscript. Support was provided by NSF OCE 0002968, NSF ANT0228895, and NSF OISE-0240092 to S. W. Wilhelm, NSF OISE 0238615 to R. M. L. McKay, and NSF 0327730 to M. R. Twiss. C. E. Mioni wishes to acknowledge support from a University of Tennessee Center for Environmental Biotechnology Graduate Fellowship, a Ryan Kelley Memorial scholarship from the International Women's Fishing Association 2003, and a Daniel Jouvance Award "Recherches sur le plancton marin 2003."

\section{References}

Achilles, K. M., T. M. Church, S. W. Wilhelm, G. W. Luther, and D. A. Hutchins (2003), Bioavailability of iron to Trichodesmium colonies in the western subtropical Atlantic Ocean, Limnol. Oceanogr., 48(6), 22502255.

Andrews, S. C., A. K. Robinson, and F. Rodriguez-Quiñones (2003), Bacterial iron homeostasis, FEMS Microbiol. Rev., 27(2-3), 215-237.

Arrieta, J. M., M. G. Weinbauer, C. Lute, and G. J. Herndl (2004), Response of bacterioplankton to iron fertilization in the Southern Ocean, Limnol. Oceanogr., 49(3), 799-808.

Beardall, J., E. Young, and S. Roberts (2001), Approaches for determining phytoplankton nutrient limitation, Aquat. Sci., 63(1), 44-69.

Berges, J. A., D. J. Franklin, and P. J. Harrison (2001), Evolution of an artificial seawater medium: Improvements in enriched seawater, artificial water over the last two decades, J. Phycol., 37(6), 1138-1145.

Bishop, J. K. B., T. J. Wood, R. E. Davis, and J. T. Sherman (2004), Robotic observations of enhanced carbon biomass and export at $55^{\circ} \mathrm{S}$ during SOFeX, Science, 304(5669), 417-420.

Bowie, A. R., M. T. Maldonado, R. D. Frew, P. L. Croot, E. P. Achterberg, R. F. C. Mantoura, P. J. Worsfold, C. S. Lawand, and P. W. Boyd (2001), The fate of added iron during a mesoscale fertilisation experiment in the Southern Ocean, Deep Sea Res., Part II, 48(11-12), 2703-2743.

Boyd, P. W., et al. (2000), A mesoscale phytoplankton bloom in the polar Southern Ocean stimulated by iron fertilization, Nature, 407(6805), 695702.

Boyd, P. W., A. C. Crossley, G. R. DiTullio, F. B. Griffiths, D. A. Hutchins, B. Quéguiner, P. N. Sedwick, and T. W. Trull (2001), Control of phytoplankton growth by iron supply and irradiance in the subantarctic Southern Ocean: Experimental results from the SAZ Project, J. Geophys. Res., 106(C12), 31,573-31,583.

Boyd, P. W., G. McTainsh, V. Sherlock, K. Richardson, S. Nichol, M. Ellwood, and R. Frew (2004), Episodic enhancement of phytoplankton stocks in New Zealand subantarctic waters: Contribution of atmospheric and oceanic iron supply, Global Biogeochem. Cycles, 18, GB1029, doi:10.1029/2002GB002020.

Boyd, P. W., et al. (2005), FeCycle: Attempting an iron biogeochemical budget from a mesoscale SF6 tracer experiment in unperturbed low iron waters, Global Biogeochem. Cycles, doi:10.1029/2005GB002494, in press.

Braun, V., and K. Hantke (1997), Receptor = mediated bacterial iron transport, in Transition Metals in Microbial Metabolism, edited by G. Winkelmann and C. J. Carrano, pp. 81-116, Harwood Acad., New York.

Bruland, K. W., R. P. Franks, G. Knauer, and J. H. Martin (1979), Sampling and analytical methods for the determination of copper, cadmium, zinc and nickel in seawater, Anal. Chim. Acta, 105(1), 233-245.

Buesseler, K. O., J. E. Andrews, S. M. Pike, and M. A. Charette (2004), The effect of iron fertilization on carbon sequestration in the Southern Ocean, Science, 304(5669), 414-417.

Coale, K. H., et al. (1996), A massive phytoplankton bloom induced by an ecosystem-scale iron fertilization experiment in the equatorial Pacific Ocean, Nature, 383(6600), 495-501.

Coale, K. H., et al. (2004), Southern ocean iron enrichment experiment: Carbon cycling in high- and low-Si waters, Science, 304(5669), 408414.

Corston, R., and A. M. Colman (Eds.) (2003), One-way analysis of variance, in A Crash Course in SPSS for Windows Versions 10 and 11, 2nd ed., pp. 74-82, Blackwell, Malden, Mass.

Danielsson, L. G., B. Magnusson, and S. Westerlund (1978), Improved metal extraction procedure for determination of trace-metals in sea-water by atomic absorption spectrometry with electrothermal atomization, Anal. Chim. Acta, 98(1), 47-57.

Dugdale, R. C., and F. P. Wilkerson (1998), Silicate regulation of new production in the equatorial Pacific upwelling, Nature, 391(6664), $270-273$.
Eldridge, M. L., C. G. Trick, M. B. Alm, G. R. DiTullio, E. L. Rue, K. W. Bruland, D. A. Hutchins, and S. W. Wilhelm (2004), Phytoplankton community response to a manipulation of bioavailable iron in HNLC waters of the subtropical Pacific Ocean, Aquat. Microb. Ecol. Proc. Conf., 35(1), 79-91.

Ellwood, M. J. (2004), Zinc and cadmium speciation in subantarctic waters east of New Zealand, Mar. Chem., 87(1-2), 37-58.

Escolar, L., J. Pérez-Martin, and V. De Lorenzo (1999), Opening the iron box: Transcriptional metalloregulation by the Fur protein, J. Bacteriol. 181(20), 6223-6229.

Firme, G. F., E. L. Rue, D. A. Weeks, K. W. Bruland, and D. A. Hutchins (2003), Spatial and temporal variability in phytoplankton iron limitation along the California coast and consequences for $\mathrm{Si}, \mathrm{N}$, and $\mathrm{C}$ biogeochemistry, Global Biogeochem. Cycles, 17(1), 1016, doi:10.1029/ $2001 \mathrm{~GB} 001824$.

Geider, R. J., and J. Laroche (1994), The role of iron in phytoplankton photosynthesis, and the potential for iron-limitation of primary productivity in the sea, Photosynth. Res., 39(3), 275-301.

Gerringa, L. J. A., H. J. W. de Baar, and K. R. Timmermans (2000), A comparison of iron limitation of phytoplankton in natural oceanic waters and laboratory media conditioned with EDTA, Mar. Chem., 68(4), 335346.

Gervais, F., U. Riebesell, and M. Y. Gorbunov (2002), Changes in primary productivity and chlorophyll a in response to iron fertilization in the Southern Polar Frontal Zone, Limnol. Oceanogr., 47(5), 1324-1335.

Greene, R. M., Z. S. Kolber, D. G. Swift, N. W. Tindale, and P. G. Falkowski (1994), Physiological limitation of phytoplankton in the eastern equatorial Pacific determined from variability in the quantum yield of fluorescence, Limnol. Oceanogr., 39(5), 1061-1074.

Hobbie, J. E., R. J. Daley, and S. Jasper (1977), Use of nucleopore filters for counting bacteria by fluorescence microscopy, Appl. Environ. Microbiol., 33(5), 1225-1228.

Hutchins, D. A., V. M. Franck, M. A. Brzezinski, and K. W. Bruland (1999a), Inducing phytoplankton iron limitation in iron-replete coastal waters with a strong chelating ligand, Limnol. Oceanogr., 44(4), 10091018.

Hutchins, D. A., A. E. Witter, A. Butler, and G. W. Luther (1999b), Competition among marine phytoplankton for different chelated iron species, Nature, 400(6747), 858-861.

Hutchins, D. A., B. J. Campbell, M. T. Cottrell, and S. Takeda (2001a), Response of marine bacterial community composition to iron additions in three iron-limited regimes, Limnol. Oceanogr., 46(6), 1535-1545.

Hutchins, D. A., P. N. Sedwick, G. R. DiTullio, P. W. Boyd, B. Quéguiner, F. B. Griffiths, and C. Crossley (2001b), Control of phytoplankton growth by iron and silicic acid availability in the subantarctic Southern Ocean: Experimental results from the SAZ Project, J. Geophys. Res. 106(C12), 31,559-31,572.

Johnson, K. S., R. M. Gordon, and K. H. Coale (1997), What controls dissolved iron concentrations in the world ocean?, Mar. Chem., 57(34), 137-161.

Kirchman, D. L. (1996), Microbial ferrous wheel, Nature, 383(6598), $303-$ 304.

Maldonado, M. T., and N. M. Price (1999), Utilization of iron bound to strong organic ligands by plankton communities in the subarctic Pacific Ocean, Deep Sea Res., Part II, 46(11-12), 2447-2473.

McKay, R. M. L., W. Wilhelm, J. Hall, D. A. Hutchins, M. M. D. Al-Rshaidat, C. E. Mioni, S. Pickmere, D. Porta, and P. W. Boyd (2005), Impact of phytoplankton on the biogeochemical cycling of iron in subantarctic waters southeast of New Zealand during FeCycle, Global Biogeochem. Cycles, 19, GB4S24, doi:10.1029/2005GB002482.

Measures, C. I., and S. Vink (2001), Dissolved Fe in the upper waters of the Pacific sector of the Southern Ocean, Deep Sea Res., Part II, 48(19-20), $3913-3941$

Meyer, J.-M., and D. Hohnabel (1992), Use of nitriloacetic acid (NTA) by Pseudomonas species through iron metabolism, Appl. Microbiol. Biotechnol., 37(1), 114-118.

Mioni, C. E., A. M. Howard, J. M. DeBruyn, N. G. Bright, M. R. Twiss, B. M. Applegate, and S. W. Wilhelm (2003), Characterization and field trials of a bioluminescent bacterial reporter of iron bioavailability, Mar. Chem., 83(1-2), 31-46.

Pakulski, J. D., R. B. Coffin, C. A. Kelley, S. L. Holder, R. Downer, P. Aas, M. M. Lyons, and W. H. Jeffrey (1996), Iron stimulation of Antarctic bacteria, Nature, 383(6596), 133-134.

Poorvin, L., J. M. Rinta-Kanto, D. A. Hutchins, and S. W. Wilhelm (2004), Viral release of iron and its bioavailability to marine plankton, Limnol. Oceanogr., 49(5), 1734-1741.

Price, N. M., G. I. Harrison, J. G. Hering, R. J. M. Hudson, P. M. V. Nirel, B. Palenik, and F. M. M. Morel (1988/1989), Preparation and chemistry 
of the artificial algal culture medium: Aquil, Biol. Oceanogr., 6, 443461.

Price, N. M., B. A. Ahner, and F. M. M. Morel (1994), The equatorial Pacific Ocean: Grazer-controlled phytoplankton populations in an ironlimited ecosystem, Limnol. Oceanogr., 39(3), 520-534.

Raven, J. A. (1990), Prediction of Mn and Fe use efficiencies of phototrophic growth as a function of light availability for growth and of $\mathrm{C}$ assimilation pathway, New Phytol., 116(1), 1-18.

SOLAS (2005), SOLAS Science Implementation plan (2005), report, SOLAS Int. Plann. Off., Univ. of East Anglia, Norwich, U.K.

Strzepek, R. F., and P. J. Harrison (2004), Photosynthetic architecture differs in coastal and oceanic diatoms, Nature, 431(7009), 689-692.

Strzepek, R., F. M. T. Maldonado, J. L. Higgins, J. Hall, S. W. Wilhelm, K. Safi, and P. W. Boyd (2005), Spinning the "Ferrous Wheel" The importance of the microbial community in an iron budget during the FeCycle experiment, Global Biogeochem. Cycles, 19, GB4S26 doi:10.1029/2005GB002490.

Sunda, W. G., and S. A. Huntsman (1997), Interrelated influence of iron, light and cell size on marine phytoplankton growth, Nature, 390(6658), 389-392.

Takata, H., et al. (2004), Spatial variability of iron in the surface water of the northwestern North Pacific Ocean, Mar. Chem., 86(3-4), 139-157.

Tortell, P. D., M. T. Maldonado, J. Granger, and N. M. Price (1999), Marine bacteria and biogeochemical cycling of iron in the oceans, FEMS Microbiol. Ecol., 29(1), 1-11.

Tsuda, A., et al. (2003), A mesoscale iron enrichment in the western Subarctic Pacific induces a large centric diatom bloom, Science, 300(5621), 958-961.

Venter, J. C., et al. (2004), Environmental genome shotgun sequencing of the Sargasso sea, Science, 304(5667), 66-74.

Weaver, R. S., D. L. Kirchman, and D. A. Hutchins (2003), Utilization of iron/organic ligand complexes by marine bacterioplankton, Aquat. Microb. Ecol. Proc. Conf., 31(3), 227-239.
Weinberg, E. (1998), Patho-ecological implications of microbial acquisition of host iron, Rev. Med. Microbiol., 9(3), 171-178.

Wells, M. L., and C. G. Trick (2004), Controlling iron availability to phytoplankton in iron-replete coastal waters, Mar. Chem., 86(1-2), 1-13. Welschmeyer, N. A. (1994), Fluorometric analysis of chlorophyll a in the presence of chlorophyll $b$ and pheopigments, Limnol. Oceanogr., 39(8), $1985-1992$

Wilhelm, S. W. (1995), Ecology of iron-limited cyanobacteria: A review of physiological responses and implications for aquatic systems, Aquat. Microb. Ecol. Proc. Conf., 9(3), 295-303.

Wilhelm, S. W., and C. A. Suttle (1999), Viruses and nutrient cycles in the sea, BioScence, 49(10), 781-788.

Wilhelm, S. W., and C. G. Trick (1994), Iron-limited growth of cyanobacteria: Multiple siderophore production is a common response, Limnol. Oceanogr., 39(8), 1979-1984.

P. W. Boyd, National Institute of Water and Atmosphere, Dunedin, New Zealand. (pboyd@alkali.otago.ac.nz)

M. J. Ellwood, National Institute of Water and Atmosphere, Hillcrest, Hamilton, New Zealand. (m.ellwood@niwa.co.nz)

S. M. Handy, College of Marine Sciences, University of Delaware, Lewes, DE 19958, USA. (shandy@udel.edu)

C. E. Mioni and S. W. Wilhelm, Department of Microbiology and Center for Environmental Biotechnology, University of Tennessee, Knoxville, TN 37996-0845, USA. (mioni@utk.edu; wilhelm@utk.edu)

R. M. L. McKay, Department of Biological Sciences, Bowling Green State University, Bowling Green, OH 43403, USA. (rmmckay@bgnet. bgsu.edu)

M. R. Twiss, Department of Biology, Clarkson University, Potsdam, NY 13699, USA. (mtwiss@clarkson.edu) 